Published in final edited form as:

J Youth Adolesc. 2017 April ; 46(4): 898-913. doi:10.1007/s10964-016-0615-y.

\title{
Personal Identity Development in Hispanic Immigrant Adolescents: Links with Positive Psychosocial Functioning, Depressive Symptoms, and Externalizing Problems
}

\author{
Seth J. Schwartz ${ }^{1}$, Jennifer B. Unger ${ }^{2}$, Alan Meca1 ${ }^{1}$, Elma I. Lorenzo-Blanco ${ }^{3}$, Lourdes \\ Baezconde-Garbanati ${ }^{2}$, Miguel Ángel Cano ${ }^{4}$, Brandy Piña-Watson ${ }^{5}$, José Szapocznik ${ }^{1}$, \\ Byron L. Zamboanga ${ }^{6}$, David Córdova ${ }^{7}$, Andrea J. Romero ${ }^{8}$, Tae Kyoung Lee ${ }^{1}$, Daniel W. \\ Soto $^{2}$, Juan A. Villamar ${ }^{9}$, Karina M. Lizzi ${ }^{1}$, Sabrina E. Des Rosiers ${ }^{10}$, and Monica \\ Pattarroyo ${ }^{2}$ \\ ${ }^{1}$ Department of Public Health Sciences, Leonard M. Miller School of Medicine, University of \\ Miami, 1120 N.W. 14th Street, Suite 1083, Miami 33136 FL, USA \\ ${ }^{2}$ University of Southern California, Los Angeles 90007 CA, USA \\ ${ }^{3}$ University of South Carolina, Columbia 29208 SC, USA \\ ${ }^{4}$ Florida International University, 11200 SW 8th St, Miami 33199 FL, USA \\ ${ }^{5}$ Texas Tech University, 2500 Broadway, Lubbock 79409 TX, USA \\ ${ }^{6}$ Smith College, Northampton 01063 MA, USA \\ ${ }^{7}$ University of Michigan, 500 S State St, Ann Arbor 48109 MI, USA \\ 8University of Arizona, Tucson 85721 AZ, USA \\ ${ }^{9}$ Northwestern University, 633 Clark St, Evanston 60208 IL, USA \\ ${ }^{10}$ Barry University, 11300 NE 2nd Ave, Miami 33161 FL, USA
}

\begin{abstract}
The present study was designed to examine trajectories of personal identity coherence and confusion among Hispanic recent-immigrant adolescents, as well as the effects of these trajectories on psychosocial and risk-taking outcomes. Personal identity is extremely important in anchoring young immigrants during a time of acute cultural change. A sample of 302 recently immigrated (5 years or less in the United States at baseline) Hispanic adolescents $\left(\mathrm{M}_{\mathrm{age}}=14.51\right.$
\end{abstract}

Correspondence to: Seth J. Schwartz.

Authors' Contributions S.J.S. wrote the grant application that funded the project, served as co-principal investigator, and led the drafting of the manuscript. J.B.U. served as co-principal investigator and contributed to manuscript preparation. A.M. and T.K.L. conducted the study analyses. E.I.L.-B., L.B.C.-G., M.A.C., B.P.-W., J.S., B.L. Z., D.C., and A.J.R. made substantive contributions to editing and revising the manuscript. D.W.S., J.A.V., K.M.L., S.E.D.R., and M.P. managed the data collection and oversaw the day-today project activities.

Conflict of Interest The authors declare that they have no competing interests.

Ethical Approval The study was approved by the Institutional Review Boards at the University of Miami and the University of Southern California, as well as by the Research Review Boards at the participating school districts.

Informed Consent Informed consent was obtained from parents, and informed assent was obtained from adolescents. Adolescents who turned 18 during the course of the study were asked to provide informed consent. 
years at baseline; $\mathrm{SD}=0.88$ years, range $14-17$ ) from Miami and Los Angeles (47\% girls) completed measures of personal identity coherence and confusion at the first five waves of a sixwave longitudinal study; and reported on positive psychosocial functioning, depressive symptoms, and externalizing problems at baseline and at Time 6 . Results indicated that identity coherence increased linearly across time, but that there were no significant changes in confusion over time and no individual differences in confusion trajectories. Higher baseline levels of, and improvements in, coherence predicted higher levels of self-esteem, optimism, and prosocial behavior at the final study timepoint. Higher baseline levels of confusion predicted lower selfesteem, greater depressive symptoms, more aggressive behavior, and more rule breaking at the final study timepoint. These results are discussed in terms of the importance of personal identity for Hispanic immigrant adolescents, and in terms of implications for intervention.

\section{Keywords}

Personal identity; Hispanic; Immigrant; Self-esteem; Depressive symptoms; Identity and externalizing behavior problems

\section{Introduction}

Identity development is a key task of adolescence and the transition to adulthood (Arnett and 2000; Erikson 1950). The biological, cognitive, and social changes that occur in early adolescence typically prompt youth to consider who they are, what and whom they identify with, what they think of themselves, and what they want to do with their lives. Early identity development in adolescence often involves balancing one's newfound self-knowledge and coherence with a sense of uncertainty or confusion about who one is and where one is headed (Schwartz et al. 2014a). It can also involve distancing oneself from parental norms (at least to some extent). Erikson 1950 posited identity as a dynamic interplay between coherence and confusion, where healthy identity development is represented as a preponderance of coherence over confusion. Erikson is clear that coherence and confusion are not necessarily opposites and can coexist within the same individual. This definition allows for identity coherence and confusion to be studied as separate but overlapping variables.

More or less, identity coherence represents what youth know about themselves and how this knowledge is integrated by them across the various domains of functioning. For example, an adolescent may know that she or he is extraverted, is a dedicated student, and identifies as Hispanic. Adolescents may view themselves as champions for other Hispanic people given their outgoing personality and strong commitment to their schoolwork. Confusion, on the other hand, represents what is not known —or yet to be integrated—about the self. Youth may not be sure what they want to become in the future, what kind of people they would want to date, and what kinds of religious or spiritual beliefs they hold. They may also be exploring their ethnic identity, and trying to decide whether they want to identify more with their parents and traditional Hispanic roots, or whether they identify more with their American friends. Confusion also refers to adolescents feeling uncomfortable about the intersection of various aspects of their identities, or of what they know or do not know about 
themselves, as well as potential changes in that identity over time. For example, adolescents who have not chosen a career path may be unsure about what their schoolwork is leading toward. So coherence refers to a sense of knowing who one is, both in terms of individual commitments, qualities, or traits and in terms of how the various aspects of oneself fit together (Erikson 1950,1968) and in relationship to others. Confusion refers to a sense of feeling "mixed up" or uncomfortable about oneself-in terms of specific content domains or in terms of how one's various self-aspects fit together (Côté and Levine 2014).

Erikson's notion of "preponderance" suggests that identity coherence and confusion operate at least somewhat independently and may have separate effects on positive psychosocial functioning, depressive symptoms, and externalizing problems. This contention has been supported cross-sectionally (Schwartz et al. 2005; Syed et al. 2013) and longitudinally. Longitudinal work (e.g., Schwartz et al. 2008, 2009a) has suggested that, although identity confusion generally decreases during the course of adolescence, increases in identity confusion during adolescence may predict externalizing behaviors such as tobacco, alcohol, and illicit drug use.

\section{Identity Coherence and Confusion}

Broadly, identity coherence represents a sense of comfort and satisfaction with the sense of self that one has developed — and as a result it would be expected to facilitate indices of positive adjustment and to protect against internalizing and externalizing symptoms. In contrast, identity confusion is destabilizing and undermines one's sense of consistency across time and place (Erikson 1968). Confusion would, therefore, be expected to interfere with positive developmental outcomes and to predict internalizing and externalizing symptoms. In many ways, identity coherence and confusion are conceptually similar to the "certainty" and "uncertainty" dimensions included in other perspectives on identity development (e.g., Meeus et al. 2010). Within the Meeus et al. 2010 model, for example, both certainty and uncertainty are necessary for determining a given individual's identity profile. Even within a specific content, one can be certain about some aspects of one's commitments but uncertain about others. An adolescent might be confident that he wants to become a doctor, for example, but he may have doubts about whether he will be able to handle the responsibilities associated with this profession. He may also worry that the years of schooling required to become a doctor may interfere with his desire to start a family.

It should be noted that prior longitudinal work on identity coherence and confusion has been conducted on intervention datasets, rather than data from natural-history longitudinal cohort studies. Intervention studies often use different inclusion/exclusion criteria, and are characterized by different rates of and reasons for attrition, compared to longitudinal cohort studies (e.g., Prado et al. 2006). To address this limitation in the extant literature, in the present study we used a natural-history longitudinal dataset to study the course of identity development among recently immigrated Hispanic adolescents. The purpose of our study was to map the developmental course of identity development among recently arrived Hispanic adolescents, as well as its effects on positive psychosocial functioning, depressive symptoms, and externalizing problems. To our knowledge, the present study is the first longitudinal examination of personal identity among Hispanic immigrant adolescents. 
It is essential to examine identity as a predictor of both positive and negative adolescent outcomes (e.g., Luyckx et al. 2006; Syed et al. 2013). Such outcomes can include positive psychosocial functioning (e.g., self-esteem, optimism, prosocial attitudes or behaviors), depressive symptoms, and externalizing problems-including conduct problems, aggression, and substance use. Using a range of outcomes is critical because it helps to inform both prevention (targeted toward reducing the likelihood of experiencing negative outcomes) and promotion (targeted toward facilitating the emergence of positive outcomes; Lerner 2015). The present study was one of the first to examine trajectories of personal identity development and their effects on a range of positive and negative outcomes within an important population-Hispanic immigrant adolescents-for whom identity issues may be especially salient.

\section{Identity Development in Hispanic Immigrant Adolescents}

Identity development may be a particularly complex process among individuals from immigrant and minority groups (Azmitia et al. 2008). Specifically, immigrants and minority group members must make sense of themselves culturally (e.g., deciding what it means to be Hispanic and how their ethnic group fits into the larger national context, and how Hispanic or not they want to be, how much Spanish they want to speak) as well as focus on more general identity domains such as career, relationships, and values (Syed and Juang 2014). Achieving identity coherence, and minimizing identity confusion, may therefore be more difficult for immigrant and minority adolescents because of the greater amount of identity work required of them as compared to majority-group adolescents. Personal identity is of great importance to adolescents from immigrant backgrounds-indeed, Schwartz et al. 2006 have argued that personal identity can anchor young people during times of acute cultural change (see Meca et al. 2016, for supportive empirical evidence). That is, personal identity can provide stability during a cultural transition. Further, aspects of one's life that were taken for granted in the country of origin—such as cultural customs and assumptions about the ways in which people are supposed to interact with one another-become important components of one's identity once one is embedded within a society where most people follow a different set of cultural norms (Smith et al. 2013).

Hispanics in the United States (U.S.) represent an important immigrant and emerging majority group in which to study personal identity. Hispanics are not only the largest (17 \% of the total U.S. population in 2014; U.S. Census Bureau 2015), and among the fastest growing (responsible for more than half of all U.S. population growth between 2000 and 2013; Bernstein 2013), U.S. ethnic minority group, but they are also at the center of divisive political debates regarding the ways in which Hispanic immigration may represent a threat to the national fabric of the U.S. (Buchanan 2011; Chavez 2013). For example, Hispanic immigrants are likely to be viewed as competing with working-class non-Hispanic Whites and African Americans for jobs (Murphey et al. 2014), and many Americans view Spanish as a threat to the status of English as the U.S. national language (symbolic threats; Ortman and Shin 2011). This complex sociopolitical position of Hispanics, combined with a perception of being "unwanted" in the U.S., may create a context that complicates the process of identity development for many Hispanic immigrant youth (Meca and Schwartz 2016). 
Previous cross-sectional and longitudinal work with Hispanic adolescents suggests that identity confusion predicts externalizing problems (Schwartz et al. 2005; Schwartz et al. 2009a). These studies did not focus on recent immigrants—instead, participants were a mix of first- and second-generation immigrant adolescents. It is possible that, within the context of recent international migration, a sense of identity coherence can help to anchor the person and to promote positive developmental outcomes (as well as to prevent negative outcomes such as depressive symptoms and externalizing problems; Dien 2000). The present study was designed to test this hypothesis, as well as to extend prior work (Schwartz et al. 2009a) suggesting that identity confusion represents a risk for depressive symptoms and externalizing problems, as well as compromised positive psychosocial functioning, among Hispanic adolescents. Indeed, the context of recent immigration may increase the importance of identity coherence. Immigrant youth may confront especially severe (and complex) identity issues, and may be faced with especially destabilizing contextual and cultural changes.

Adolescence is a time of both increased risk and increased opportunities for positive development (Lerner et al. 2003). For some youth, optimism, civic engagement, and other positive outcomes increase during adolescence (Callina et al. 2014). For some youth, adolescence is a time of increased internalizing (e.g., depressive symptoms) and externalizing (e.g., aggressive behavior, rule breaking, and substance use) symptoms (Ames et al. 2015; Castelao and Kröner-Herwig 2014). These two sets of behaviors are sometimes inversely related over time, and sometimes they are not inversely related (or may even be positively related; Arbeit et al. 2014). Schwartz 2016 has suggested that identity helps to differentiate between those youth who follow more positive, more negative, or "mixed" developmental trajectories. As a result, it is essential to include both indicators of positive development (e.g., self-esteem, optimism, prosocial behavior), and indicators of internalizing and externalizing behaviors, as outcomes of identity development among youth.

\section{The Present Study}

In the present study, we tested the hypothesis proposed by Schwartz et al. 2006 using a twosite, six-wave longitudinal cohort study of Hispanic immigrant adolescents and their families. To provide a more complete representation of the U.S. Hispanic population than would be available in any one geographic area, we sampled from Miami and Los Angeles, two major metropolitan areas that receive large numbers of Hispanic immigrants. These two cities differ in many important ways, including region of the U.S., primary Hispanic subgroups (primarily Cuban, Nicaraguan, and Colombian in Miami vs. primarily Mexican, Guatemalan, and Salvadoran in Los Angeles), and receptivity toward new arrivals. For example, Miami is known to be especially friendly to Hispanic immigrants, whereas Los Angeles provides a somewhat more ambivalent context of reception (Hayes-Bautista 2004; Stepick et al. 2003).

Within this recent-immigrant sample, we pursued two primary research objectives. First, we examined the trajectories of adolescent identity coherence and confusion across the first five timepoints. Second, we examined the ways in which these trajectories predicted indicators of 
positive psychosocial functioning (self-esteem, optimism, and prosocial behavior), depressive symptoms, externalizing problems (rule breaking and aggressive behavior), and substance use (tobacco and alcohol) at the sixth study timepoint, controlling for baseline scores on these outcome variables. As part of these objectives, we also tested for longitudinal invariance in all of our study variables-because longitudinal invariance is a prerequisite for growth curve modeling (Little 2013).

Based on prior work and on theoretical formulations, we anticipated that confusion would decrease, and that coherence would remain stable, over time (Erikson 1950; Schwartz et al. 2009a). Regarding effects of identity trajectories on outcome variables, we expected that increases in coherence would predict greater positive psychosocial functioning and lower depressive symptoms, externalizing problems, and substance use. Conversely, we expected that increases in confusion would predict lower positive psychosocial functioning and more depressive symptoms and externalizing problems.

\section{Method}

\section{Participants}

The current study was part of a larger longitudinal project involving personal identity, acculturation, family functioning, and psychosocial and health outcomes among recently immigrated Hispanic adolescents and their families. The project was called Construyendo Oportunidades Para los Adolescentes Latinos (COPAL; Schwartz et al. 2015). Each adolescent participated in the larger project with her or his primary parent or guardian, although only adolescent data are used in the present article. Participants in the current study were 302 recent-immigrant Hispanic adolescents ( $53 \%$ boys; $\mathrm{M}_{\mathrm{age}}=14.51$ years at baseline; $\mathrm{SD}=0.88$ years, range $14-17$ ). As per inclusion criteria, all adolescents had arrived in the U.S. within five years of the baseline data collection and were either finishing or entering the ninth grade. Adolescents in Miami $(n=152)$ had been in the U.S. for a median of 1 year (interquartile range $=0-3$ years), whereas adolescents in Los Angeles ( $n=$ 150) had been in the U.S. for a median of 3 years (interquartile range $=1-4$ years).

The Miami sample was primarily from Cuba (61\%), the Dominican Republic (8\%), Nicaragua (7\%), Honduras (6\%), Colombia (6\%), and other Hispanic countries (12\%); the Los Angeles sample was primarily from Mexico (70 \%), El Salvador (9\%), Guatemala (6\%), and other Hispanic countries (15\%). The mean annual household income, as reported by parents, was $\$ 30,854$ (SD $\$ 10,824)$. Demographic differences between the Miami and Los Angeles samples are reported elsewhere (Schwartz et al. 2015).

\section{Procedures}

Baseline data were gathered during the Summer and Fall of 2010, and subsequent timepoints occurred during Spring 2011, Fall 2011, Spring 2012, Fall 2012, and Spring 2013.

Participants were recruited from randomly selected public schools in heavily Hispanic areas in Miami-Dade and Los Angeles counties. Because we were interested in recent-immigrant families, and because many Hispanic immigrants tend to settle in heavily Hispanic areas (Portes and Rumbaut 2006; Stepick et al. 2003), we selected schools where the student body 
was at least $75 \%$ Hispanic. Our goal was to recruit 25 students per school for a total of 150 families per site. In cases where a school or district did not provide at least 25 students, we recruited additional students from another nearby high school. The study was approved by the Institutional Review Boards at the University of Miami and the University of Southern California, and by the Research Review Committees for each of the participating school districts.

At each school, we first obtained approval from the principal or vice-principal to conduct the study at her or his school. In Miami, because the majority of new Hispanic immigrant students are enrolled in English for Speakers of Other Languages (ESOL) classes, we gave a brief presentation in each ESOL class about the study and asked interested students to provide their primary caregiver's phone number. We also gave presentations in the basiclevel English classes into which students would transition after completing the ESOL program. In Los Angeles, we also approached students in ESOL classes-but because students in California are transferred out of ESOL after one year, we also recruited from the larger student body. In some Los Angeles schools, principals were able to supply us with a list of students who had been in the U.S. for five years or less. In Miami, 10 schools participated, and the number of participating students within each school ranged from 1 to $57(\mathrm{Mdn}=9, \mathrm{IQR}=4-19)$. In Los Angeles, 13 schools participated, and the number of students participating from each school ranged from 1 to $27(\mathrm{Mdn}=12, \mathrm{IQR}=4-16)$.

Staff members called parents to verify that the adolescent had been in the U.S. for less than five years and that the family did not plan to move out of the South Florida or Southern California area during the course of the study. Parents whose adolescents met these inclusion criteria were invited to schedule evening or weekend assessment appointments at a convenient location. We received contact information for 632 adolescents who met the study's inclusion criteria. Of these, 197 were unreachable, primarily because of incorrect or non-working telephone numbers. The remaining 435 families were reached by telephone and invited to participate. Of these 435 families, $69 \%(n=302)$ participated in the study. A total of 133 families met inclusion criteria and were contacted, but did not participate: 93 (65\%) of these families reported work or scheduling conflicts; 18 (13\%) missed at least three scheduled assessment appointments; 1 (1\%) was planning to move; $2(2 \%)$ reported experiencing serious health problems; and $19(14 \%)$ declined but did not provide a reason. Adolescents received a movie ticket for each timepoint in which they participated.

Parents and adolescents provided informed consent and assent, respectively. Parents and adolescents were taken to separate rooms so that the consent/assent process could be conducted privately. In cases where adolescents declined to provide assent, parents were told that the family did not meet inclusion criteria (to protect the adolescent's privacy). Each participant completed the assessment battery in English or Spanish, according to her or his preference. Eighty-four percent of adolescents completed their assessments in Spanish at baseline. This percentage decreased to $77 \%$ at Time 2, $72 \%$ at Time 3,66 \% at Time 4, $68 \%$ at Time 5, and $71 \%$ at Time 6. Empirical evidence (Schwartz et al. 2014a) suggests that it is likely safe to pool acculturation data across languages of assessment. Assessments were completed using an audio computer-assisted interviewing (A-CASI) system (Turner et al. 1998) on laptop computers. The system displays each item and response choices on the 
computer screen while the item and response choices are read to the participant through a set of headphones.

Following Knight et al. 2009, rigorous tracking procedures were used to maintain contact with participants between assessment timepoints. At baseline, we obtained the names and contact information for three "contact persons" who would know how to reach the family if we were unable to do so. Names and phone numbers for these contact persons were updated at each assessment timepoint. Our assessors also called each family approximately once every $2-3$ months to say hello and to ensure that our current contact information for the family was still correct. As a result of these tracking procedures, we were able to retain $85 \%$ of the sample ( 256 of the original 302 families) across the six study waves. In the present analyses, we used maximum likelihood procedures so that all 302 cases could be included in analysis.

\section{Measures}

Unless otherwise specified, 5-point Likert scales were used for all study measures, with response options ranging from 1 (Strongly Disagree) to 5 (Strongly Agree). Alpha coefficients presented here are from the current sample across relevant time points and for both English and Spanish versions. All measures were developed using a two-step translation process (Sireci et al. 2006) whereby measures are translated by one translator from English to Spanish, back-translated by a second translator (Spanish to English), and then evaluated by both translators to resolve discrepancies. We also took a great deal of care to ensure that the Spanish versions of the measures would be understandable to speakers of both Cuban and Mexican Spanish. Where possible, generic, "broadcast" terms were used, and we avoided colloquial expressions that would be unfamiliar to any of the nationalities in our study. Where necessary, we used both the "Cuban" and "Mexican" expressions within a single item.

Coherence and confusion-The 12-item identity subscale from the Erikson Psychosocial Stage Inventory (EPSI; Rosenthal et al. 1981) was used to assess personal identity coherence and confusion. Six items are worded in a "positive" direction towards coherence ( $\mathrm{a}=.69-.87$; Sample item: "I know what kind of person I am"), and 6 items are worded in a "negative" direction towards confusion ( $\alpha=.62-.77$; Sample item: "I don't really know who I am"). Prior analyses have not only established the validity of the measure in Spanish (Schwartz et al. 2014b) but also supported the two-factor structure, even after controlling for potential methodological effects of item wording (Schwartz et al. 2009b). Items for this measure are provided in Table 1.

Positive psychosocial functioning-We assessed this construct in terms of selfesteem, optimism, and prosocial behavior.

Self-esteem: The 10-item Rosenberg Self-Esteem Scale (RSES; Rosenberg 1968) was used to measure self-esteem ( $a=.72-.84$; Sample item: "On the whole, I am happy with myself"). This measure has been used widely with Spanish-speaking samples (Schmitt and Allik 2005). 
Optimism: The 6-item Children's Hope Scale (CHS; Edwards et al. 2007) was used to measure optimism ( $a=.87-.95$; Sample item: "I think I am doing pretty well"). This measure, designed specifically for use with Hispanics, evaluates the extent to which young people are optimistic about their future.

Prosocial behavior: Prosocial behavior was measured using an adapted version the Prosocial Tendencies Measure (Carlo and Randall 2002). The version that we used consists of 19 items assessing the extent to which participants typically help others in a number of situations-including altruistic (where the identity of the helper will not be known to the recipient), highly emotional, dire need, and when helping others will make the helper "look good." We derived a total score $(\alpha=.86)$ by summing responses to all 19 items. A sample item is "I like helping others because it makes me look good." The Prosocial Tendencies Measure has been used successfully with Hispanic adolescents (Carlo et al. 2010).

Depressive symptoms-The 20-item Center for Epidemiologic Studies Depression Scale (CES-D; Radloff 1977) assessed adolescents' depressive symptoms ( $a=.81-.89$, sample item: "I felt sad this week"). Items are rated on a 4-point scale ranging from 1 (Seldom) to 4 (Most of the Time) and ask participants how often they experienced various depressive symptoms during the week prior to assessment. The CES-D has been translated into Spanish and used frequently with Hispanic individuals (e.g., Todorova et al. 2010).

Externalizing problems-We assessed this construct in terms of rule breaking, physical aggression, and tobacco and alcohol use.

Aggressive behavior and rule breaking: The Youth Self-Report (YSR; Achenbach and Rescorla 2001) was used to assess adolescents' aggressive (17 items, $a=.87-.93$, sample item: "I physically attack people") and rule breaking (15 items, $a=.87-.92$, sample item: "I lie or cheat") behaviors. Response choices ranged from 0 (Not true) to 2 (often or very true). The YSR has been validated with Spanish-speaking adolescents (Lopez et al. 2008).

Tobacco and alcohol use: Tobacco and alcohol use were assessed using a modified version of the Monitoring the Future survey (Johnston et al. 2014). Adolescents were asked about frequency of tobacco and alcohol use during the 90 days prior to each assessment point.

\section{Results}

Plan of Analysis

Following Little (2013), the present analyses proceeded in five primary steps. First, we conducted longitudinal invariance analyses to ensure that the study constructs were equivalent across time. As noted above, longitudinal invariance is a prerequisite for growth curve modeling (Little 2013), in that the same variable (with the same conceptual and empirical meaning) is assumed to have been measured at each timepoint. Additionally, because we estimated effects of the identity coherence and confusion growth parameters on Time 6 outcome variables controlling for baseline levels of these outcomes, it is also essential to ensure that the outcomes have equivalent conceptual and empirical meaning across time. 
Our second step of analysis was to compute descriptive statistics for identity coherence and confusion at each of the first five timepoints, and for the outcome variables at Times 1 and 6. Third, we estimated a growth curve model for identity coherence and confusion from Time 1 to Time 5. Next, we estimated a model where intercept and slope terms for identity coherence and confusion between Times 1 and 5 were allowed to predict outcome variables at Time 6, controlling for these same outcomes at Time 1. Finally, we ascertained whether any of the effects we reported differed across sites. To do this, we compared an unconstrained model (with all paths free to vary across site) to a constrained model (with each path constrained to be equal across site) using the likelihood ratio test to evaluate the null hypothesis of equivalent findings across sites. Age, gender, and years in the U.S. were controlled in all analyses. All analyses were conducted using Mplus release 7.1 (Muthén and Muthén 1998-2015). Full information maximum likelihood estimation was used so that cases with missing data could be included in analysis.

\section{Longitudinal Invariance Tests}

To test for longitudinal measurement invariance, we used standard invariance testing procedures (see Dimitrov 2010, for a review). We tested for three levels of invarianceconfigural, metric, and scalar. Configural invariance indicates that the number of factors, and the patterning of items onto their respective subscales, is consistent across time. The assumption of configural invariance is tested by estimating a model with the factor structure (items loading onto their respective subscale factors) specified at each timepoint, but with no additional constraints applied. A finding of acceptable fit for the configural invariance model indicates that the assumption of equal form - that the same general model fits the data at each timepoint — can be retained. Metric invariance indicates that the factor loadings between items and subscales are equal across time. This assumption is tested by comparing the configural invariance model against a metric invariance model where each factor loading is constrained equal across timepoints. A nonsignificant difference in fit between the configural and metric invariance models indicates that the assumption of metric invariance can be retained. Scalar invariance indicates that the item intercepts are equivalent across time. This assumption is tested by comparing the metric invariance model against a scalar invariance model with both factor loadings and item intercepts constrained equal across timepoints. A nonsignificant difference in fit between the metric and scalar invariance models indicates that the assumption of scalar invariance can be retained.

For both metric and scalar invariance, it is possible to reach a conclusion of partial invariance (Hancock 2004). Partial invariance indicates that a majority, but not all, of the loadings or intercepts are equivalent across time. A conclusion of partial invariance can also be reached if the overall invariance test indicates a significant difference in fit between models, but no one loading or intercept is found to be responsible for the difference in fit.

Differences between the configural and metric invariance models, and between the metric and scalar invariance models, were tested using multigroup confirmatory factor analyses. The fit of the models with vs. without a set of constraints (constraints on factor loadings or on item intercepts) is compared using the differences in the comparative fit index (CFI) and root mean square error of approximation (RMSEA) between models (Knight and Zerr 2010). 
If neither of these differences equals or exceeds .010, then the assumption of metric or scalar invariance (whichever is being evaluated in a given model comparison) can be retained.

Results of the longitudinal invariance tests are provided in Table 2. For identity coherence, the configural invariance model fit the data adequately, $\chi^{2}(335)=667.30 ; \mathrm{CFI}=.907$; RMSEA $=.057$. There was some evidence of metric noninvariance, $\Delta \mathrm{CFI}=.012 ; \Delta \mathrm{RMSEA}$ $=.002$. However, when we examined the individual factor loadings, no single loading met criteria for noninvariance. As a result, we reached a conclusion of partial metric invariance. We found evidence for full scalar invariance, $\Delta$ CFI $<.001 ; \Delta$ RMSEA $<.001$.

For identity confusion, the configural invariance model fit the data well, $\chi^{2}(335)=464.97$; $\mathrm{CFI}=.949$; RMSEA $=.036$. we found evidence for full metric invariance, $\Delta \mathrm{CFI}=.005$; $\triangle$ RMSEA $=.002$. However, there was some evidence for scalar noninvariance, $\Delta \mathrm{CFI}=.019$; $\triangle$ RMSEA $<.004$. When we examined the items one at a time, the item "I don't really know who I am" appeared to violate the assumption of scalar invariance, $\triangle \mathrm{CFI}=.011 ; \triangle \mathrm{RMSEA}$ $=.039$. Because the other five items on the confusion subscale met criteria for scalar invariance, we assumed partial scalar invariance.

As noted above, for outcome variables we tested for invariance using only the Time 1 and 6 data. For self-esteem, the configural invariance model fit the data adequately, $\chi^{2}(139)=$ 247.64; CFI $=.936$; RMSEA $=.051$. The assumption of metric invariance appeared to be violated, $\Delta \mathrm{CFI}=.011 ; \triangle \mathrm{RMSEA}=.002$; but none of the individual items met criteria for noninvariance. The assumption of scalar invariance also appeared to be violated, $\Delta \mathrm{CFI}=$. 085; $\triangle \mathrm{RMSEA}=.022$. Follow-up analyses indicated that the item "I wish I could have more respect for myself" did not meet criteria for scalar invariance, $\Delta \mathrm{CFI}=.047 ; \Delta \mathrm{RMSEA}=$. 012. No other items violated the assumption of scalar invariance, so we reached a conclusion of partial scalar invariance.

For optimism, the configural invariance model fit the data well, $\chi^{2}(47)=87.48$; CFI $=.970$; RMSEA $=.053$. The assumption of metric invariance was supported, $\Delta \mathrm{CFI}=.002$; $\triangle \mathrm{RMSEA}=.001$. The assumption of scalar invariance was statistically violated, $\Delta \mathrm{CFI}=$. 016; $\triangle \mathrm{RMSEA}=.008$, but follow-up analyses did not identify any items that appeared to be responsible for the lack of scalar invariance. We therefore reached a conclusion of partial scalar invariance.

For prosocial behavior, the configural invariance model provided an acceptable fit to the data, $\chi^{2}(565)=1,050.52$; CFI $=.903$; RMSEA $=.053$. We found evidence for full metric invariance, $\Delta \mathrm{CFI}=.004 ; \triangle \mathrm{RMSEA}<.001$, but the assumption of scalar invariance was violated, $\Delta \mathrm{CFI}=.022 ; \triangle \mathrm{RMSEA}=.004$. Follow-up analyses did not identify any items that appeared to account for the lack of scalar invariance-and as a result, we concluded that we had partial scalar invariance.

For depressive symptoms, the configural invariance model provided adequate fit to the data, $\chi^{2}(703)=1,352.46 ; \mathrm{CFI}=.906 ; \mathrm{RMSEA}=.055$. Criteria for full metric, $\Delta \mathrm{CFI}=.004$; $\triangle \mathrm{RMSEA}=.001$, and scalar, $\Delta \mathrm{CFI}=.004 ; \Delta \mathrm{RMSEA}<.001$, invariance were satisfied. 
For aggressive behavior, the configural invariance model provided adequate fit to the data, $\chi^{2}(499)=771.39 ; \mathrm{CFI}=.902$; RMSEA $=.043$. The assumption of metric invariance was statistically rejected, $\triangle \mathrm{CFI}=.018 ; \triangle \mathrm{RMSEA}=.002$-although no individual items appeared to account for the lack of invariance. The assumption of scalar invariance was also statistically rejected, $\triangle \mathrm{CFI}=.012 ; \triangle \mathrm{RMSEA}=.002$, though again no individual items appeared to be responsible for the lack of invariance. We therefore concluded that we had partial metric and partial scalar invariance.

For rule breaking, the configural invariance model provided adequate fit to the data, $\chi^{2}$ $(380)=622.88 ; \mathrm{CFI}=.902 ; \mathrm{RMSEA}=.046$. The assumption of metric invariance was retained, $\triangle \mathrm{CFI}=.004 ; \triangle \mathrm{RMSEA}<.001$, but the assumption of scalar invariance was not, $\Delta \mathrm{CFI}=.011 ; \Delta \mathrm{RMSEA}=.002$. No individual items appeared to be responsible for the lack of invariance, so we reached a conclusion of partial scalar invariance.

\section{Descriptive Statistics}

Tables 3 and 4 display means and standard deviations (for identity variables and continuous outcome variables) or frequencies (for categorical variables). Across the sample as a whole, there was not much mean-level change in identity variables between Time 1 and Time 5 . Self-esteem increased significantly between Times 1 and 5, $t(240)=2.50, p<.02$, Hedges' $g=.19$; as did optimism, $t(240)=3.71, p<.001$, Hedges' $g=.28$. No other changes in descriptive statistics were statistically significant.

\section{Linear Growth Curve Modeling}

Our next step of analysis was to estimate a linear growth curve model on the identity coherence and confusion data. Although there was no mean-level change in identity coherence or confusion, significant variability around the mean would still allow intercept and slope terms to predict outcome variables (Little 2013). We used robust maximum likelihood estimation (MLR; Satorra and Bentler 1994) to account for non-normality. Four indices were used to evaluate model fit: the comparative fit index (CFI), the non-normed fit index (NNFI), the root mean square error of approximation (RMSEA), and the standardized root mean square residual (SRMR). Good model fit is defined as CFI $\geq .95$, NNFI $\geq .95$, RMSEA $\leq .05$, and SRMR $\leq .06$, whereas adequate fit is defined as CFI $\geq .90$, NNFI $\geq .90$, RMSEA $\leq .08$, and SRMR $\leq .10$ (Kline 2010). The use of four fit indices leaves open the possibility that some indices might suggest good fit whereas others suggest adequate fit. Methodologists (e.g., West et al. 2012) have recommended reporting the chi square statistic, but not using it in interpretation, because it is often overpowered and tests the null hypothesis of perfect fit to the data. The chi square is therefore almost always significant in large samples and complex models.

To identify the appropriate growth parameters to include, we began with separate interceptonly models for coherence and for confusion (Widaman and Thompson 2003). From there, we proceeded to estimate separate linear growth curve models for coherence and for confusion. Again separately for coherence and for confusion, we compared these models compared against each other using the likelihood ratio test to determine whether the slope terms significantly improved model fit. Finally, using the intercepts and the slope terms 
indicated by the model comparisons, we evaluated a dual-process growth curve model (i.e., a single model with growth parameters for two sets of indicator variables) including both coherence and confusion. A dual-process model allows for the two sets of growth parameters to predict outcomes while still controlling for Type I error inflation-because all terms are included in a single structural model.

With regard to identity coherence, there was a significant difference in fit between the linear growth curve model and the intercept-only model $[\Delta-2 \operatorname{LL}(3)=36.86, p<.001]$. Moreover, the linear growth curve model provided adequate fit to the data, $\chi^{2}(10)=16.80, p<.001$; $\mathrm{CFI}=.96 ; \mathrm{NNFI}=.96 ; \mathrm{RMSEA}=.047(90 \% \mathrm{CI}=.001$ to .086$)$; SRMR $=.087$. The mean slope for coherence was statistically significant $(-.29, p<.001)$ with significant variability around this slope $\left(s^{2}=.46, p=.006\right)$. For identity confusion, results indicated a nonsignificant difference between the linear growth curve model and the intercept model $[\Delta-2 \mathrm{LL}(3)=6.27, p=.099]$. Moreover, not only was the mean slope for confusion statistically nonsignificant $(-.06, p=.10)$, but there was also no significant variability around the mean confusion slope $\left(s^{2}=.43, p=.093\right)$.

To test for the possibility of non-linear growth trajectories in identity coherence and confusion, we added quadratic and cubic slope terms for both coherence and confusion. None of these terms were significantly different from zero (means ranged from .01 to .06, all $p s>.22$ ), and none was characterized by significant variability around the mean (variances ranged from 0.18 to 2.16 , all $p s>.13$ ).

Building on these models, we proceed to evaluate a dual-process model for identity coherence and confusion. Given the non-significant linear slope parameter (and nonsignificant variability around this slope) for identity confusion, the confusion slope parameter was removed from the growth curve model. The model provided adequate fit to the data, $\chi^{2}(46)=82.09, p<.001 ; \mathrm{CFI}=.92 ; \mathrm{NNFI}=.92 ; \mathrm{RMSEA}=.051(90 \% \mathrm{CI}=.032$ to .068$) ; \mathrm{SRMR}=.079$. Once again, the mean linear slope for coherence was statistically significant $(-.29, p<.001)$ with significant variability around this slope (coherence, $s^{2}=.44$, $p=.007$ ). Additionally, the coherence and confusion intercepts were significantly and negatively interrelated, $r=-.55, p<.001$.

\section{Bivariate Correlations}

Table 5 provides bivariate correlations for identity coherence and confusion growth parameters as well as for Time 6 outcome variables. It is worth noting that the intercepts for coherence and confusion were correlated at $r=-.71\left(r^{2}=.50\right)$, which indicates that only half of the variability in error-free baseline levels of coherence and confusion is shared between these two indices. Intercept terms for coherence and confusion were significantly correlated with many of the Time 6 outcome variables. Correlations accounting for more than $10 \%$ shared variability emerged for the coherence intercept with Time 6 self-esteem and prosocial behavior, and for the confusion intercept with Time 6 self-esteem (negatively), depressive symptoms, and aggressive behavior. 


\section{Longitudinal Predictive Model}

We then estimated a model where intercepts and slopes for identity coherence between Times 1-5, and the intercept for confusion, were allowed to predict each of the outcome variables at Time 6 , controlling for the outcomes at Time 1 . Because modeling categorical outcomes in MLR requires numerical integration and often leads to model non-convergence, we saved the latent variable factor scores in Mplus and used them as observed variables in subsequent model tests. Moreover, because modeling categorical outcomes in MLR does not produce fit indices due to its reliance on numerical integration (Muthén and Muthén 19982012), we first estimated the model without the dichotomous health risk outcomes to ascertain model fit. This model provided acceptable fit: $\chi^{2}(57)=124.29, p<.001 ; \mathrm{CFI}=$. 92 ;NFI $=.89 ; \mathrm{RMSEA}=.063(90 \% \mathrm{CI}=.048$ to .078$)$; $\mathrm{SRMR}=.045$. We then added the categorical outcomes.

Standardized path estimates for continuous variables, and odds ratios for categorical outcome variables, are displayed in Table 6. For positive psychosocial functioning, depressive symptoms, and aggression and rule breaking, the identity confusion intercept was the primary predictor-predicting five of these six outcomes. The coherence intercept and linear slope parameters both positively predicted self-esteem, optimism, and prosocial behavior. The identity coherence intercept approached significance as a negative predictor of the cigarette use likelihood.

\section{Invariance Across Sites}

Finally, we sought to ascertain whether any of the effects differed between the Miami and Los Angeles sites. To test for site differences, we compared an unconstrained model (with all paths free to vary across site) to a constrained model (with each path constrained to be equal across site) using the likelihood ratio test to evaluate the null hypothesis of equivalent findings across sites. Because it is computed using the difference between the likelihood ratios for the constrained and unconstrained models, this test provides only a chi square difference and does not provide any of the other SEM fit indices. We found a significant difference in fit between these two models, $\Delta \chi^{2}(24)=47.20, p=.003$. As a result, we proceeded to examine each path for consistency across site by constraining one path at a time and examining the change in the log likelihood value. These follow-up analyses indicated several significant differences (see Table 7).

Specifically, findings indicated three significant differences across the two sites. For the Los Angeles sample only, the coherence intercept was found to positively predict self-esteem. Additionally, the confusion intercept more strongly predicted depressive symptoms for adolescents in Los Angeles than for adolescents in Miami. Finally, whereas the linear coherence slope parameter was protective against cigarette use among adolescents in Miami, this slope parameter strongly and positively predicted cigarette use among adolescents in Los Angeles. 


\section{Discussion}

The present study was conducted to track the development of personal identity among recently arrived Hispanic adolescents in Miami and Los Angeles. Personal identity represents a key challenge during adolescence, in that young people are tasked with defining who they are within the specific social, contextual, and cultural spaces in which they live (Côté and Levine 2014; Erikson 1968). Among immigrants, personal identity may be especially important, given that it may represent a source of stability during a time of acute cultural change (Meca et al. 2016; Schwartz et al. 2006).

We used a six-wave longitudinal design to track the development of identity coherence and confusion over time. Following Erikson 1950, identity coherence was operationalized as a sense of comfort and self-knowledge, and identity confusion was operationalized as a sense of uneasiness and fragmentation. At the overall level, identity coherence decreased over time, whereas confusion did not change. There was significant variability around the coherence slope, but no statistically reliable changes or individual differences in confusion over time. Interestingly, this pattern of results for recently immigrated adolescents was the opposite of the pattern observed among longer-term and second-generation Hispanic adolescents, where confusion decreased and coherence did not change (Schwartz et al. 2009a). In the present results, coherence and confusion were remarkably stable across time. In particular, there was no change over time in identity confusion, and no variability across participants in this flat slope. This lack of change in identity variables may further reflect the role of personal identity as an "anchor" for recently immigrated Hispanic adolescents.

Supporting Erikson's 1950, 1968 theorizing, coherence and confusion were negatively interrelated in terms of baseline scores (intercepts). However, the lack of association between slope terms - due to the absence of change or individual differences in confusion over time-is not consistent with what Erikson would have predicted. Nonetheless, the baseline correlation, which represents $50 \%$ shared variability, suggests that coherence and confusion represent interrelated, but still separate, components of personal identity for the recently immigrated Hispanic adolescents in our sample. As Erikson speculated, these adolescents were challenged with balancing certainty (coherence) with uncertainty (confusion). Certainty appeared to be more important than uncertainty in predicting outcomes over time, however. The lack of changes in confusion over time was unexpected, especially inasmuch as Erikson would have predicted decreases in confusion across adolescence. It is possible that, among recent immigrant adolescents, increases in coherence - and not decreases in confusion - are what helps to successfully carry the individual through the experience of cultural transition.

Findings for effects of personal identity trajectories on outcomes were consistent with identity theory (e.g., Côté and Levine 2014; Erikson 1968). Higher baseline levels of identity confusion predicted lower levels of self-esteem and higher levels of depressive symptoms, rule breaking, and aggressive behavior. Baseline levels of coherence predicted self-esteem, optimism, and prosocial behavior 3 years later, and increases in coherence predicted selfesteem, optimism, prosocial behavior at the final timepoint. 
These findings are also consistent with what would be expected within neo-Eriksonian theories of identity. For example, we know that adaptive identity processes-especially making and identifying with commitments to future life plans-are positively linked with self-esteem and negatively linked with internalizing and externalizing symptoms (Luyckx et al. 2006). On the other hand, processes that may facilitate identity confusion, such as ruminating over possible life choices and chronically reconsidering one's commitments, are predictive of lowered self-esteem and of internalizing and externalizing symptoms (Luyckx et al. 2008; Schwartz et al. 2012). These parallels between the current findings and those obtained with neo-Eriksonian identity models suggest avenues for intervention, as we discuss below. Promoting commitment formation, and a sense of solidarity with the commitments one has enacted, may help to promote the positive well-being that appears to result from identity coherence. At the same time, helping young people to avoid ruminating over prospective life alternatives - and to avoid chronically questioning their choices - may help to prevent the negative outcomes that appear to result from identity confusion.

Although the majority of study findings were consistent across the Miami and Los Angeles sites, four of our findings did differ across sites. In two of these cases (coherence intercept predicting self-esteem and confusion intercept predicting depressive symptoms), the effects were in the same direction at both sites but were stronger in Los Angeles. In one case, effects were in opposing directions across sites-the coherence slope predicted cigarette smoking negatively in Miami but positively in Los Angeles. In the fourth case (coherence slope predicting rule breaking), the effect was not statistically significant at either site but the two coefficients were significantly different from each other. In essence, then, in two of the three cases where findings differed across sites, and the effect was significant and in the expected direction at both sites. The difference was in the strength of the effects. Because recently immigrated Hispanic adolescents in Los Angeles may perceive a more hostile context of reception compared to adolescents in Miami, personal identity may play a stronger role in facilitating self-esteem and protecting against depressive symptoms in Los Angeles (cf. Schwartz et al. 2006). In the only case where an effect was significant at one site but not the other-coherence slope predicting cigarette smoking - the effect should be interpreted in light of the small number of smokers ( $n=8$ at baseline and $n=10$ at Time 6) in the sample. It is possible that, although increases in personal identity coherence were largely facilitative of positive outcomes and protective against internalizing and externalizing symptoms, a small number of Los Angeles adolescents may have turned to cigarettes to help them cope with stressors associated with cultural adjustment.

All of these findings, except for the positive effect of confusion intercept on prosocial behavior and the positive effect of coherence slope on cigarette smoking in Los Angeles, are consistent with Erikson's (1950;s (1968) theorizing and suggest that his framing of identity development as a dynamic between coherence and confusion applies reasonably well to recently arrived Hispanic adolescents. As has been the case in other adolescent and emerging adult samples (Schwartz et al. 2009a; Schwartz et al. 2010), baseline confusion levels were strongly predictive of low self-esteem, internalizing symptoms, and externalizing problems. Further, perhaps because the initial years following immigration are likely characterized by heightened levels of uncertainty (Smokowski and Bacallao 2010), confusion does not appear to decrease over time (as may be normative in other Hispanic 
adolescent samples; Schwartz et al. 2009a). We do not know, however, whether our findings would have been different with a younger or older cohort of adolescents. That is, would confusion have shown more change over time for adolescents who immigrated at older or younger ages?

Contrary to our expectations, the personal identity variables were not especially predictive of substance use. The only significant associations that emerged differed across site: increases in coherence predicted lower odds of cigarette use in Miami, but greater odds of cigarette use in Los Angeles. Cigarettes have become less normative in recent years, and perhaps as a result, in Miami adolescents with greater levels of coherence in the ninth grade were less likely to smoke later on. The opposite finding that emerged in Los Angeles is difficult to explain and appears to require further in-depth research.

\section{Limitations and Future Directions}

The present findings should be interpreted in light of at least three important limitations. First, the time span examined in the present study is fairly brief ( 3 years). It would be important to follow these adolescents into emerging adulthood, when the majority of risk taking occurs (see Arnett 2015, for a collection of reviews). Second, all variables were selfreported by adolescents. Although the longitudinal design and controls for baseline outcome scores may help to correct for some of the shared method variance that results from using only one source of data (Cole and Maxwell 2003), future work should utilize at least some outcomes reported by peers, teachers, or other informants. Third, although Miami and Los Angeles are major destinations for Hispanic immigrants, many Hispanics are also immigrating to "new receiving communities" outside of traditional gateway cities and states (Ennis et al. 2011). For example, states such as North Carolina, South Carolina, Tennessee, and Arkansas had relatively small Hispanic populations in 2000 and experienced the largest percentage increase in their Hispanic populations between 2000 and 2011 (Brown and Lopez 2013). These states likely have less experience with Hispanic immigration compared to traditional gateway areas-and it is possible that this lack of experience and receptivity may translate into more difficulty for Hispanic immigrant adolescents. It would be important to replicate the present findings in these types of communities, as well as in different subgroups of Hispanics—such as children of seasonal workers and those who reside in predominantly African American communities.

\section{Practical Implications}

The present results may have important implications for the design of identity-focused interventions. These findings, along with those reported by Schwartz et al. (2009a), suggest that reducing identity confusion in early adolescence is an important goal for identityfocused interventions. Given that coherence overlapped only partially with confusion, intervening to promote increased coherence may not necessarily offset the effects of confusion on well-being, internalizing, and externalizing outcomes. Intervention activities and programs for Hispanic adolescents should be specifically designed to reduce confusion. Eichas et al. (2014) review a range of strategies that could be employed to decrease levels of confusion among Hispanic adolescents. As suggested above, activities to promote the enactment of, and adherence to, commitments may be important in facilitating coherence; 
whereas activities designed to reduce rumination and self-doubts may be important in reducing confusion. Using a largely Hispanic sample, Schwartz et al. (2005) found that intervention programs designed to help young people sort through their life choices and potential alternatives, as well as to help young people identify the goals and activities that are most consistent with their "true self," showed promise in promoting adaptive identity processes. It is essential to conduct rigorous controlled studies on these strategies to ascertain the extent to which they can be manualized and disseminated. It is also possible that family-based interventions focusing on increasing parental involvement and parentadolescent communication (e.g., Prado et al. 2007) may affect identity coherence and confusion through their effects on family processes.

\section{Conclusion}

The present study has demonstrated that Erikson's identity theory-particularly the interplay of coherence and confusion-is applicable to, and important for, recently arrived Hispanic adolescents. In particular, levels of identity confusion occurring shortly after immigration predict low self-esteem, higher depressive symptoms, and greater externalizing problems over time. Although most of the identity-related work conducted with this population has focused on cultural dimensions of identity, our results suggest that personal identity also has considerable relevance to psychosocial and behavioral outcomes. We hope that our work will inspire more research on trajectories of personal identity among immigrant youth, for whom personal identity may be just as critical—if not more so—as it is for other youth. Such future work will be essential in understanding the ways in which personal identity contributes to facilitating positive developmental outcomes, and to preventing problematic outcomes, among immigrant youth. Such efforts may help immigrant youth to make a maximal contribution to the society in which they are coming of age.

\section{Acknowledgments}

Funding Preparation of this article was supported by Grant DA026594 (Seth J. Schwartz and Jennifer B. Unger, Co-Principal Investigators) from the National Institute on Drug Abuse.

\section{Biographies}

Seth J. Schwartz is Professor of Public Health Sciences at the University of Miami Leonard M. Miller School of Medicine. His research interests include identity, acculturation, ethnicity, health risk behaviors, well-being, and prevention science.

Jennifer B. Unger is a Professor of Preventive Medicine at the University of Southern California. Her research interests include adolescent health, health disparities, and tobacco control.

Alan Meca is a Postdoctoral Associate at the Department of Public Health Sciences at the University of Miami Leonard M. Miller School of Medicine. His research interests are centered around personal and cultural identity, acculturation, health risk behaviors, and on promoting positive development in adolescence and emerging adulthood. 
Elma I. Lorenzo-Blanco is an assistant professor in Clinical/Community Psychology in the Department of Psychology at the University of South Carolina. Her research seeks to understand how acculturation or life in the United States affects the emotional and behavioral well-being of Latina/o youth, adults, and families to inform and develop culturally responsive preventive interventions.

Lourdes Baezconde-Garbanati, $\mathrm{PhD}$, MPH is Professor in Preventive Medicine at the Keck School of Medicine of the University of Southern California. Her research interests include culture and health risk behaviors, health disparities, social determinants of health, acculturation, ethnicity, health promotion and disease prevention, and community health sciences.

Miguel Ángel Cano is an Assistant Professor of epidemiology at the Robert Stempel College of Public Health \& Social Work at Florida International University. His research interests include social and ethnocultural determinants of health risk behaviors among underserved ethnic groups.

Brandy Piña-Watson is an assistant professor of Counseling Psychology in the Department of Psychological Sciences at Texas Tech University. Her research focuses on developing an understanding of how individual factors, family dynamics, culture and society impact Latina/o adolescent and emerging adult depression, suicidality, well-being, and academic success, with a particular focus on individuals of Mexican Descent.

José Szapocznik is Professor of Public Health Sciences, Architecture, Psychology, Educational Research and Counseling Psychology at the University of Miami. His interests include the role of family context on adolescent problem development, and the role of the built environment on physical activity and related health outcomes.

Byron L. Zamboanga is a Professor of Psychology at Smith College. His research program focuses on the cultural, cognitive, and social correlates of alcohol use among adolescents and young adults.

David Córdova is an Assistant Professor at the University of Michigan School of Social Work. His program of research focuses on the etiology of adolescent HIV/STI testing and risk behaviors, including drug use and sexual risk behaviors, and applying this research to the development and testing of preventive interventions.

Andrea J. Romero is Fitch Nesbitt Professor in Family Studies and Human Development at the University of Arizona. Her research interests are adolescent health and educational disparities with a particular focus on cultural, family, and community contexts.

Tae Kyoung Lee is Senior Research Associate at in the Department of Public Health Sciences at the University of Miami Leonard M. Miller School of Medicine. His research interests include the longitudinal assessment of adolescent psychopathology and longitudinal statistical modeling. 
Daniel W. Soto is a Project Manager at the University of Southern California, Keck School of Medicine. His research interests include adolescent health, acculturation and health disparities, health promotion, substance abuse prevention, and tobacco control.

Juan A. Villamar is Executive Coordinator for the Center for Prevention Intervention Methodology at Northwestern University. His research interests include implementation science and the delivery of evidence-based intervention programs in community practice.

Karina M. Lizzi has a master's degree in public health from the University of Miami. She served as a project director for the study from which the present data were taken.

Sabrina Des Rosiers is Assistant Professor of Psychology at Barry University. Her research interests include identity, acculturation, and health risk behaviors.

Monica Pattarroyo is a Research Associate at the University of Southern California. She was responsible for data collection for the study from which the present data were taken.

\section{References}

Achenbach, TM., Rescorla, LA. Manual for the ASEBA School-Age Forms \& Profiles. Burlington, VT: University of Vermont, Research Center for Children, Youth, and Families; 2001.

Ames ME, Wintre MG, Flora DB. Trajectories of BMI and internalizing symptoms: Associations across adolescence. Journal of Adolescence. 2015; 45:80-88. [PubMed: 26397879]

Arbeit MR, Johnson SK, Champine RB, Greenman KN, Lerner JV, Lerner RM. Profiles of problematic behaviors across adolescence: Covariations with indicators of positive youth development. Journal of Youth and Adolescence. 2014; 43:971-990. [PubMed: 24562425]

Arnett JJ. Emerging adulthood: A theory of development from the late teens through the twenties. American Psychologist. 2000; 55:469-480. [PubMed: 10842426]

Arnett, JJ. Oxford handbook of emerging adulthood. Oxford, UK: Oxford University Press; 2015.

Azmitia, M., Syed, M., Radmacher, K. Introduction and evidence from a longitudinal study of emerging adults. In: Azmitia, M.Syed, M., Radmacher, K., editors. The intersections of personal and social identities: New Directions for Child and Adolescent Development. Vol. 120. New York, NY: John Wiley and Sons; 2008.

Bernstein, R. US Census Bureau projections show a slower growing, older, more diverse nation a half century from now. 2013. Retrieved February 15, 2013 from https://www.census.gov/newsroom/ releases/archives/population/cb12-243.html

Brown, A., Lopez, MH. Ranking the Latino populations in the states. 2013. Retrieved November 3, 2016 from http://www.pewhispanic.org/2013/08/29/ii-ranking-latino-populations-in-the-states/

Buchanan, PJ. State of emergency: The third world invasion and conquest of America. New York: St. Martin's Press; 2011.

Callina CS, Johnson SK, Buckingham MH, Lerner RM. Hope in context: Developmental profiles of trust, hopeful future expectations, and civic engagement across adolescence. Journal of Youth and Adolescence. 2014; 43:869-883. [PubMed: 24531882]

Carlo G, Randall BA. The development of a measure of prosocial behaviors for late adolescents. Journal of Youth and Adolescence. 2002; 31:31-44.

Carlo G, Knight GP, McGinley M, Zamboanga BL, Jarvis LH. The multidimensionality of prosocial behavior and evidence of measurement equivalence in Mexican American and European American early adolescents. Journal of Research on Adolescence. 2010; 20:334-358.

Castelao CF, Kröner-Herwig B. Developmental trajectories and predictors of externalizing behavior: A comparison of girls and boys. Journal of Youth and Adolescence. 2014; 43:775-789. [PubMed: 24002677] 
Chavez, L. The Latino threat: Constructing immigrants, citizens, and the nation. Stanford, CA: Stanford University Press; 2013.

Cole DA, Maxwell SE. Testing mediational models with longitudinal data: Questions and tips in the use of structural equation modeling. Journal of Abnormal Psychology. 2003; 112:558-577. [PubMed: 14674869]

Côté, JE., Levine, CG. Identity formation, agency, and culture: A social psychological synthesis. 2nd. Philadelphia, PA: Taylor and Francis; 2014.

Dien DS. The evolving nature of self-identity across four levels of history. Human Development. 2000; 43:1-18.

Dimitrov DM. Testing for factorial invariance in the context of construct validation. Measurement and Evaluation in Counseling and Development. 2010; 43:121-149.

Edwards LM, Ong AD, Lopez SJ. Hope measurement in Mexican American youth. Hispanic Journal of Behavioral Sciences. 2007; 29:225-241.

Eichas, K., Meca, A., Montgomery, M., Kurtines, WM. Identity and positive youth development: Advances in developmental intervention science. In: McLean, K., Syed, M., editors. Oxford handbook of identity development. New York: Oxford University Press; 2014. p. 337-354.

Ennis, SR., Ríos-Vargas, M., Albert, NG. The Hispanic population: 2010. 2010 Census Briefs. Washington, DC: U. S. Census Bureau; 2011.

Erikson, EH. Childhood and society. New York: Norton; 1950.

Erikson, EH. Identity: Youth and crisis. New York, NY: Norton; 1968.

Hancock, GR. Experimental, quasi-experimental, and non-experimental design and analysis with latent variables. In: Kaplan, D., editor. Sage handbook of quantitative methodology for the social sciences. Thousand Oaks, CA: Sage; 2004. p. 317-334.

Hayes-Bautista, D. La Nueva California: Latinos in the Golden State. Berkeley, CA: University of California Press; 2004.

Johnston, LD., O’Malley, PM., Bachman, JG. Monitoring the future national survey results on drug use, 1975-2013: Volume I, Secondary school students. Ann Arbor: University of Michigan, Institute for Social Research; 2014. 2014

Kline, RB. Principles and practices of structural equation modeling. 3rd. New York: Guilford; 2010.

Knight GP, Zerr AA. Informed theory and measurement equivalence in child development research. Child Development Perspectives. 2010; 4:25-30.

Knight, GP., Roosa, MW., Umana-Taylor, AJ. Studying ethnic minority and economically disadvantaged populations: Methodological challenges and best practices. Washington, DC: American Psychological Association; 2009.

Lerner RM. Promoting positive human development and social justice: Integrating theory, research, and application in contemporary developmental science. International Journal of Psychology. 2015; 50:165-173. [PubMed: 25782450]

Lerner RM, Dowling EM, Anderson PM. Positive youth development: Personhood as the basis of thriving and civil society. Applied Developmental Science. 2003; 7(3):172-180.

Little, TD. Longitudinal structural equation modeling. New York: Guilford Press; 2013.

Lopez B, Schwartz SJ, Prado G, Huang S, Rothe EM, Wang W, Pantin H. Correlates of early alcohol and drug use in Hispanic adolescents: Examining the role of ADHD with comorbid conduct disorder, family, school, and peers. Journal of Clinical Child and Adolescent Psychology. 2008; 37:820-832. [PubMed: 18991132]

Luyckx K, Goossens L, Soenens B. A developmental contextual perspective on identity construction in emerging adulthood: Change dynamics in commitment formation and commitment evaluation. Developmental Psychology. 2006; 42:366-380. [PubMed: 16569174]

Luyckx K, Goossens L, Soenens B, Beyers W. Unpacking commitment and exploration: Validation of an integrative model of adolescent identity formation. Journal of Adolescence. 2006; 29:361-378. [PubMed: 15878619]

Luyckx K, Schwartz SJ, Berzonsky MD, Soenens B, Vansteenkiste M, Smits I, et al. Capturing ruminative exploration: Extending the four-dimensional model of identity formation in late adolescence. Journal of Research in Personality. 2008; 42:58-82. 
Meca, A., Schwartz, SJ. Acculturation and substance use. In: Sweeny, K., Robbins, MS., editors. Wiley encyclopedia of health psychology. New York: John Wiley and Sons; 2016. in press

Meca A, Sabet RF, Farelly C, Benitez CG, Schwartz SJ, Gonzales-Backen M, Lizzi KM. Personal and cultural identity development in recently immigrated Hispanic adolescents. Cultural Diversity and Ethnic Minority Psychology. 2016

Meeus W, van de Schoot R, Keijsers L, Schwartz SJ, Branje S. On the progression and stability of adolescent identity formation: A five-wave longitudinal study in early-to-middle and middleto-late adolescence. Child Development. 2010; 81:1565-1581. [PubMed: 20840241]

Murphey, D., Guzman, L., Torres, A. America's Hispanic children: Gaining ground, looking forward. 2014. Retrieved August 30, 2016 from http://www.childtrends.org/wp-content/uploads/ 2014/09/2014-38AmericaHispanicChildren.pdf

Muthén, LK., Muthén, BO. Mplus User's Guide. 5th. Los Angeles, CA: Muthén \& Muthén; 19982012.

Muthén, LK., Muthén, BO. Mplus User's Guide. 7th. Los Angeles, CA: Muthén \& Muthén; 19982015.

Ortman, JM., Shin, HB. Language projections: 2010 to 2020. 2011. Retrieved from http:// www.census.gov.edgekey-staging.net/content/dam/Census/library/working-papers/2011/demo/ 2011-Ortman-Shin.pdf

Portes, A., Rumbaut, RG. Immigrant America: A portrait. 3rd. Berkeley, CA: University of California Press; 2006.

Prado G, Pantin H, Briones E, Schwartz SJ, Feaster DJ, Huang S, Szapocznik J. A randomized controlled trial of a family-centered intervention in preventing substance use and HIV risk behaviors in Hispanic adolescents. Journal of Consulting and Clinical Psychology. 2007; 75:914926. [PubMed: 18085908]

Prado G, Pantin H, Schwartz SJ, Lupei NS, Szapocznik J. Predictors of engagement and retention into a parent-centered, ecodevelopmental HIV preventive intervention for Hispanic adolescents and their families. Journal of Pediatric Psychology. 2006; 31:874-890. [PubMed: 16049264]

Radloff L. The CES-D scale: A self-report depression scale for research in the general population. Applied Psychological Measurement. 1977; 1:385-401.

Rosenberg, M. Society and the adolescent self-image. Princeton, NJ: Princeton University Press; 1968.

Rosenthal DA, Gurney RM, Moore SM. From trust to intimacy: A new inventory for examining Erikson's stages of psychosocial development. Journal of Youth and Adolescence. 1981; 10:525537. [PubMed: 24310543]

Satorra, A., Bentler, PM. Corrections to test statistics and standard errors in covariance structure analysis. In: von Eye, A., Clogg, CC., editors. Latent variables analysis: Applications to developmental research. Thousand Oaks, CA: Sage; 1994. p. 399-419.

Schmitt DP, Allik J. Simultaneous administration of the Rosenberg Self-Esteem Scale in 53 nations: Exploring the universal and culture-specific features of global self-esteem. Journal of Personality and Social Psychology. 2005; 89:623-642. [PubMed: 16287423]

Schwartz SJ. Turning point for a turning point: Advancing emerging adulthood theory and research. Emerging Adulthood. 2016; 4:307-317.

Schwartz SJ, Benet-Martínez V, Knight GP, Unger JB, Zamboanga BL, Des Rosiers SE, Stephens DP, Huang S, Szapocznik J. Effects of language of assessment on the measurement of acculturation: Measurement equivalence and cultural frame switching. Psychological Assessment. 2014a; 26:100-114. [PubMed: 24188146]

Schwartz SJ, Forthun LF, Ravert RD, Zamboanga BL, Rodriguez L, UmañaTaylor AJ, Filton BJ, Kim SY, Rodriguez L, Weisskirch RS, Vernon M, Shneyderman Y, Williams MK, Agocha VB, Hudson M. Identity consolidation and health risk behaviors in college students. American Journal of Health Behavior. 2010; 34:214-224. [PubMed: 19814601]

Schwartz SJ, Klimstra TA, Luyckx K, Hale WW III, Meeus WHJ. Characterizing the self-system over time in adolescence: Internal structure and associations with internalizing symptoms. Journal of Youth and Adolescence. 2012; 41:1208-1225. [PubMed: 22402997] 
Schwartz SJ, Kurtines WM, Montgomery MJ. A comparison of two strategies for facilitating identity formation processes in emerging adults: An exploratory study. Journal of Adolescent Research. $2005 ; 20: 309-345$.

Schwartz, SJ., Luyckx, K., Crocetti, E. What have we learned since Schwartz (2001)? A reappraisal of the field. In: McLean, K., Syed, M., editors. Oxford handbook of identity development. Oxford, UK: Oxford University Press; 2014b. p. 539-561.

Schwartz SJ, Mason CA, Pantin H, Szapocznik J. Effects of family functioning and identity confusion on substance use and sexual behavior in Hispanic immigrant early adolescents. Identity: An International Journal of Theory and Research. 2008; 8:107-124.

Schwartz SJ, Mason CA, Pantin H, Szapocznik J. Longitudinal relationships between family functioning and identity development in Hispanic immigrant adolescents: Continuity and change. Journal of Early Adolescence. 2009a; 29:177-211. [PubMed: 19756226]

Schwartz SJ, Montgomery MJ, Briones E. The role of identity in acculturation among immigrant people: Theoretical propositions, empirical questions, and applied recommendations. Human Development. 2006; 49:1-30.

Schwartz SJ, Pantin H, Prado G, Sullivan S, Szapocznik J. Family functioning, identity, and problem behavior in Hispanic immigrant early adolescents. Journal of Early Adolescence. 2005; 25:392420. [PubMed: 16912809]

Schwartz SJ, Unger JB, Zamboanga BL, Szapocznik J. Rethinking the concept of acculturation: Implications for theory and research. American Psychologist. 2010; 65:237-251. [PubMed: 20455618]

Schwartz SJ, Unger JB, Zamboanga BL, Cordova D, Mason CA, Huang S, Szapocznik J. Developmental trajectories of acculturation: Links with family functioning and mental health in recent-immigrant Hispanic adolescents. Child Development. 2015; 86:726-748. [PubMed: 25644262]

Schwartz SJ, Zamboanga BL, Wang W, Olthuis JV. Measuring identity from an Eriksonian perspective: Two sides of the same coin? Journal of Personality Assessment. 2009b; 91:143-154. [PubMed: 19205935]

Sireci SG, Wang Y, Harter J, Ehrlich EJ. Evaluating guidelines for test adaptations: A methodological analysis of translation quality. Journal of Cross-Cultural Psychology. 2006; 37:557-567.

Smith, PB., Fischer, R., Vignoles, V., Bond, MH. Understanding social psychology across cultures: Engaging with others in a changing world. London: Sage; 2013.

Smokowski, PR., Bacallao, ML. Becoming bicultural: Risk, resilience, and Latino youth. New York, NY: New York University Press; 2010.

Stepick, A., Grenier, G., Castro, M., Dunn, M. This land is our land: Immigrants and power in Miami. Berkeley, CA: University of California Press; 2003.

Syed M, Juang LP. Ethnic identity, identity coherence, and psychological functioning: Testing basic assumptions of the developmental model. Cultural Diversity and Ethnic Minority Psychology. 2014; 20:176-190. [PubMed: 24773003]

Syed M, Walker LHM, Lee RM, Umaña-Taylor AJ, Zamboanga BL, Schwartz SJ, Armenta BE, Huynh Q-L. A two-factor model of ethnic identity exploration: Implications for identity coherence and well-being. Cultural Diversity and Ethnic Minority Psychology. 2013; 19:143-154. [PubMed: 23647328]

Todorova IL, Falcón LM, Lincoln AK, Price LL. Perceived discrimination, psychological distress and health. Sociology of Health and Illness. 2010; 32:843-861. [PubMed: 20649891]

Turner CF, Ku L, Rogers SM, Lindberg LB, Pleck JH, Sonsenstein LH. Adolescent sexual behavior, drug use, and violence: Increased reporting with computer survey technology. Science. 1998; 280:867-873. [PubMed: 9572724]

U.S. Census Bureau. Hispanic heritage month: Facts and features. 2015. Retrieved September 2, 2016 from http://www.census.gov/newsroom/facts-for-features/2015/cb15-ff18.html

West, SG., Taylor, AB., Wu, W. Model fit and model selection in structural equation modeling. In: Hoyle, RH., editor. Handbook of structural equation modeling. New York: Guilford Press; 2012.

Widaman KF, Thompson JS. On specifying the null model for incremental fit indices in structural equation modeling. Psychological Methods. 2003; 8:16-37. [PubMed: 12741671] 


\section{Table 1}

\section{Identity coherence and confusion items}

\begin{tabular}{l} 
Identity coherence \\
\hline I've got a clear idea of what I want to be. \\
The important things in life are clear to me. \\
I've got it together. \\
I know what kind of person I am. \\
I have a strong sense of what it means to be male/female. \\
I like myself and am proud of what I stand for. \\
Identity confusion \\
I change my opinion of myself a lot. \\
I feel mixed up. \\
I can't decide what I want to do with my life. \\
I don't really know who I am. \\
I work keep up a certain image when I'm with people. \\
I don't really feel involved.
\end{tabular}




\section{Table 2}

Invariance test results

\begin{tabular}{llll}
\hline Measure/subscale & Invariance test & & \\
\cline { 2 - 4 } & Configural & Metric & Scalar \\
\hline Identity coherence & $\chi^{2}(335)=667.30 ; \mathrm{CFI}=.907 ;$ RMSEA $=.057$ & $\Delta \mathrm{CFI}=.012 ; \Delta \mathrm{RMSEA}=.002$ & $\Delta \mathrm{CFI}<.001 ; \Delta \mathrm{RMSEA}<.001$ \\
Identity confusion & $\chi^{2}(335)=464.97 ; \mathrm{CFI}=.949 ; \mathrm{RMSEA}=.036$ & $\Delta \mathrm{CFI}=.005 ; \Delta \mathrm{RMSEA}=.002$ & $\Delta \mathrm{CFI}=.019 ; \Delta \mathrm{RMSEA}<.004$ \\
Self-esteem & $\chi^{2}(139)=247.64 ; \mathrm{CFI}=.936 ; \mathrm{RMSEA}=.051$ & $\Delta \mathrm{CFI}=.011 ; \Delta \mathrm{RMSEA}=.002$ & $\Delta \mathrm{CFI}=.085 ; \Delta \mathrm{RMSEA}=.022$ \\
Optimism & $\chi^{2}(47)=87.48 ; \mathrm{CFI}=.970 ;$ RMSEA $=.053$ & $\Delta \mathrm{CFI}=.002 ; \Delta \mathrm{RMSEA}=.001$ & $\Delta \mathrm{CFI}=.016 ; \Delta \mathrm{RMSEA}=.008$ \\
Prosocial behavior & $\chi^{2}(565)=1050.52 ; \mathrm{CFI}=.903 ;$ RMSEA $=.053$ & $\Delta \mathrm{CFI}=.004 ; \Delta \mathrm{RMSEA}<.001$ & $\Delta \mathrm{CFI}=.022 ; \Delta \mathrm{RMSEA}=.004$ \\
Depressive symptoms & $\chi^{2}(703)=1352.46 ; \mathrm{CFI}=.906 ;$ RMSEA $=.055$ & $\Delta \mathrm{CFI}=.004 ; \Delta \mathrm{RMSEA}=.001$ & $\Delta \mathrm{CFI}=.004 ; \Delta \mathrm{RMSEA}<.001$ \\
Aggressive behavior & $\chi^{2}(499)=771.39 ; \mathrm{CFI}=.902 ;$ RMSEA $=.043$ & $\Delta \mathrm{CFI}=.018 ; \Delta \mathrm{RMSEA}=.002$ & $\Delta \mathrm{CFI}=.012 ; \Delta \mathrm{RMSEA}=.002$ \\
Rule breaking & $\chi^{2}(380)=622.88 ; \mathrm{CFI}=.902 ;$ RMSEA $=.046$ & $\Delta \mathrm{CFI}=.004 ; \Delta \mathrm{RMSEA}<.001$ & $\Delta \mathrm{CFI}=.011 ; \Delta \mathrm{RMSEA}=.002$ \\
\hline
\end{tabular}

Note: Bolded values indicate that the assumption of invariance was statistically rejected 

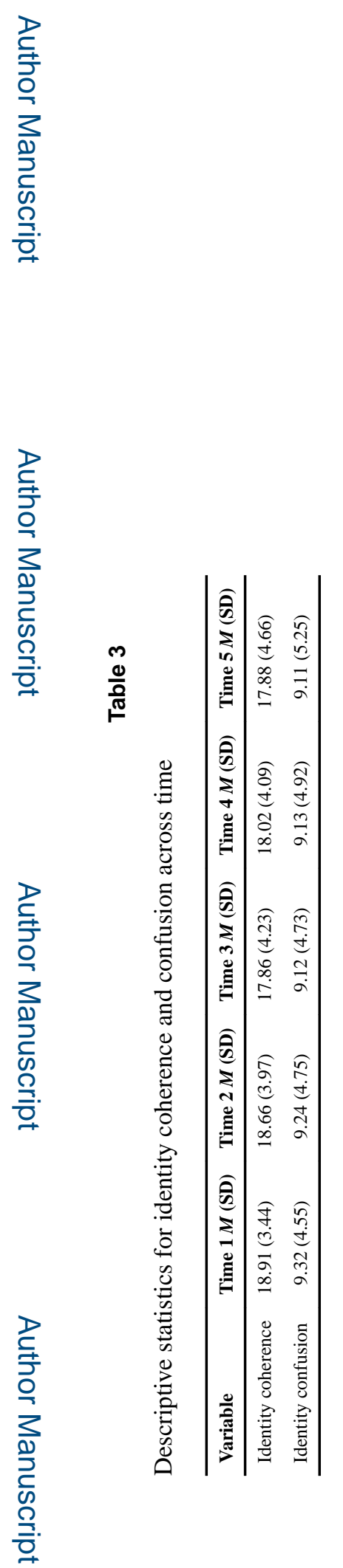


\section{Table 4}

Descriptive statistics for outcome variables at Times 1 and 6

\begin{tabular}{|c|c|c|c|}
\hline Variable & Time $1 M(\mathrm{SD})$ & Time $6 M(\mathrm{SD})$ & $t$ (Hedges' g) \\
\hline Self-esteem & $28.62(5.26)$ & $29.78(6.89)$ & $2.50 *(0.19)$ \\
\hline Optimism & $21.85(5.42)$ & $23.45(5.87)$ & $3.71^{* * *}(0.28)$ \\
\hline Prosocial behavior & $37.83(13.14)$ & $35.96(14.73)$ & $1.83(0.13)$ \\
\hline Depressive symptoms & $29.77(15.93)$ & $29.25(14.86)$ & $0.46(0.04)$ \\
\hline Aggressive behavior & $4.89(5.30)$ & $4.58(6.30)$ & $0.16(0.01)$ \\
\hline Rule breaking & $3.59(4.42)$ & $3.62(5.18)$ & $0.35(0.03)$ \\
\hline Cigarette use (Yes/No) & $2.6 \%$ & $4.0 \%$ & N/A \\
\hline Alcohol use (Yes/No) & $6.6 \%$ & $9.3 \%$ & N/A \\
\hline \multicolumn{4}{|l|}{${ }^{*}<<.05$} \\
\hline \multicolumn{4}{|l|}{${ }^{* *} p<.01$} \\
\hline $\begin{array}{l}* * * \\
p<.001\end{array}$ & & & \\
\hline
\end{tabular}

$J$ Youth Adolesc. Author manuscript; available in PMC 2018 April 01. 


\section{로을}

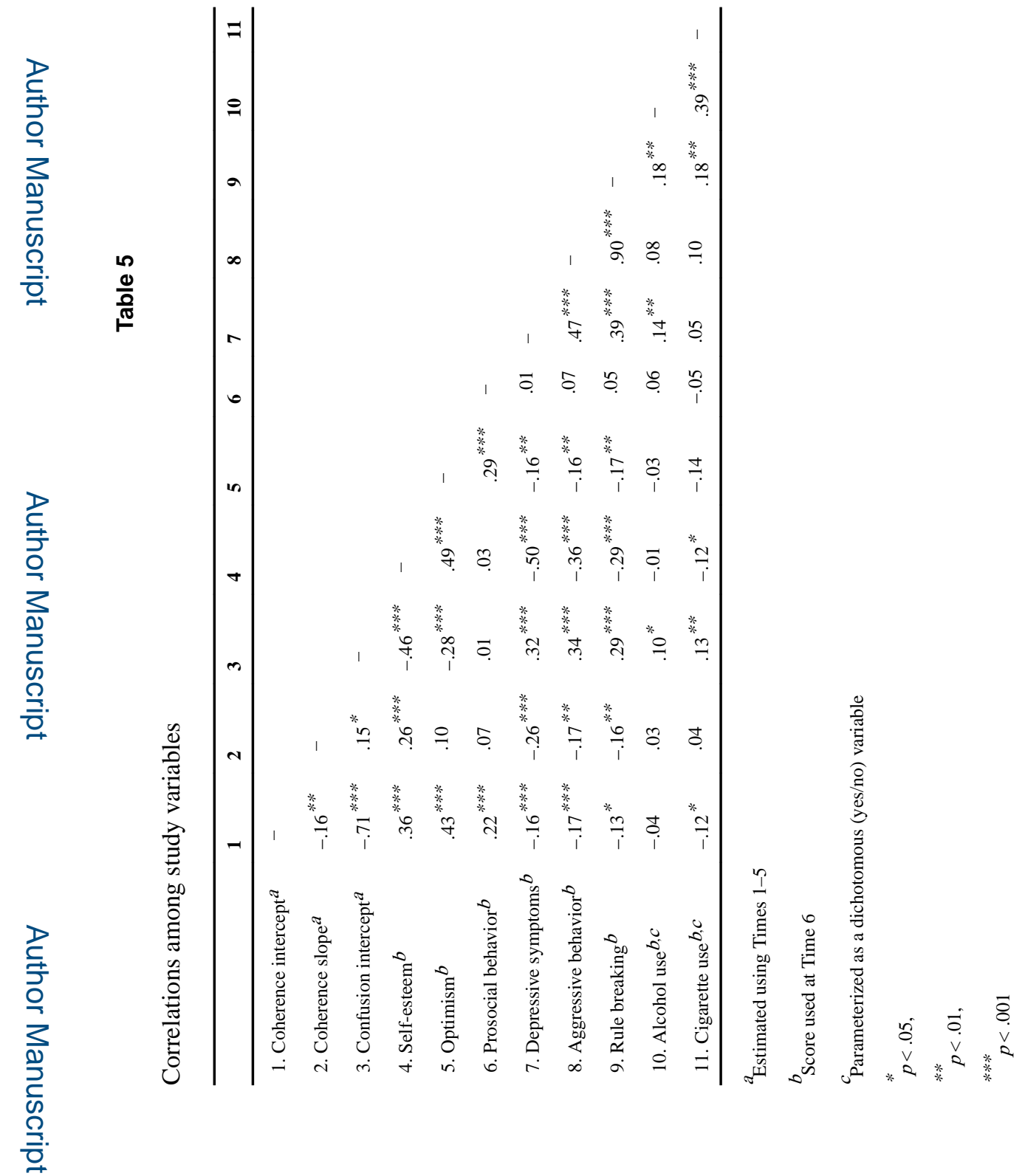

J Youth Adolesc. Author manuscript; available in PMC 2018 April 01. 


\section{Table 6}

Structural path estimates

\begin{tabular}{|c|c|c|c|}
\hline T6 Outcome & Predictor & Estimate & $95 \% \mathrm{CI}$ \\
\hline \multirow[t]{3}{*}{ Self esteem } & Coherence (I) & $.190^{* *}$ & $.015-.365$ \\
\hline & Coherence (S) & $.110^{* * *}$ & $.030-.190$ \\
\hline & Confusion (I) & $-.410^{* * * * *}$ & $-.536--.265$ \\
\hline \multirow[t]{3}{*}{ Optimism } & Coherence (I) & $.388^{* * * * *}$ & $.193-.582$ \\
\hline & Coherence (S) & $.169^{* * * *}$ & $.048-.290$ \\
\hline & Confusion (I) & .016 & $-.153-.185$ \\
\hline \multirow[t]{3}{*}{ Prosocial behavior } & Coherence (I) & $.309^{* * * *}$ & $.181-.436$ \\
\hline & Coherence (S) & $.167^{* * * * *}$ & $.090-.244$ \\
\hline & Confusion (I) & $.162^{* *}$ & $.015-.309$ \\
\hline \multirow[t]{3}{*}{ Depression T6 } & Coherence (I) & .037 & $-.058-.133$ \\
\hline & Coherence (S) & -.102 & $-.207-.003$ \\
\hline & Confusion (I) & $.396^{* * * *}$ & $.221-.572$ \\
\hline \multirow[t]{3}{*}{ Rule breaking T6 } & Coherence (I) & .034 & $-.102-.170$ \\
\hline & Coherence (S) & .039 & $-.078-.156$ \\
\hline & Confusion (I) & $.410^{* * * *}$ & $.278-.542$ \\
\hline \multirow[t]{3}{*}{ Aggression T6 } & Coherence (I) & .046 & $-.094-.185$ \\
\hline & Coherence (S) & .038 & $-.096-.173$ \\
\hline & Confusion (I) & $.351^{* * * *}$ & $.218-.484$ \\
\hline \multirow[t]{3}{*}{ Alcohol use $\mathrm{T}^{a}$} & Coherence (I) & .984 & $.833-1.162$ \\
\hline & Coherence (S) & 2.324 & $.789-6.841$ \\
\hline & Confusion (I) & 1.100 & $.957-1.264$ \\
\hline \multirow[t]{3}{*}{ Cigarette use $\mathrm{T} 6^{a}$} & Coherence (I) & $0.849^{*}$ & $.711-1.012$ \\
\hline & Coherence (S) & 1.990 & $.111-35.698$ \\
\hline & Confusion (I) & 1.070 & $.880-1.302$ \\
\hline
\end{tabular}

Notes: I intercept, $S$ slope

${ }^{a}$ Path estimates represent odds ratios. All other path estimates are standardized regression coefficients

*

$p<.10$,

*** $p<.05$,

**** $p<.01$,

***** $p<.001$

$J$ Youth Adolesc. Author manuscript; available in PMC 2018 April 01. 


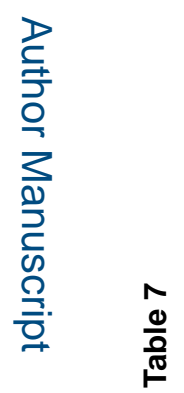

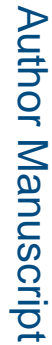

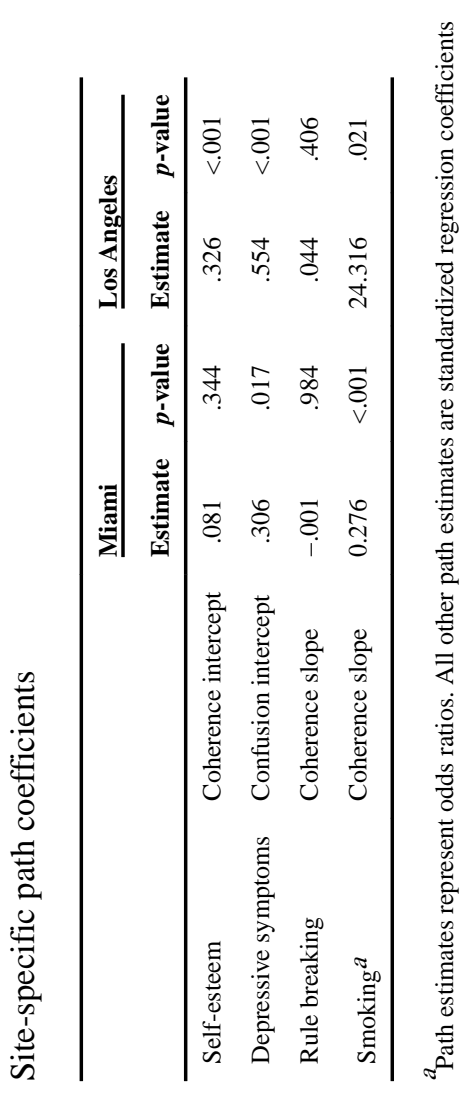

J Youth Adolesc. Author manuscript; available in PMC 2018 April 01. 